\title{
MARKETING DE RELACIONAMENTO E SOFTWARE DE CRM: ESTUDO DE CASO EM UMA CONCESSIONÁRIA DE AUTOMÓVEIS
}

\author{
Relationship marketing and CRM software: \\ A case study in a car dealer
}

Envio 28.09.09 / Aceite 10.12.09

\section{Guilherme Olkoski ${ }^{1}$ \\ Regina Uster ${ }^{2}$ \\ Licione Marques ${ }^{3}$ \\ Jaqueline Silva ${ }^{4}$}

\section{Resumo}

Devido à complexidade do mercado brasileiro, as organizações, com visão de longo prazo, procuram estabelecer um relacionamento duradouro com seus clientes em busca da fidelização e do aumento das margens de ganho por cliente ao longo do tempo. Sendo assim, este trabalho tem como objetivo avaliar os resultados estratégicos da gestão de clientes através do Customer Relationship Management (CRM) e do Marketing de Relacionamento na rede de concessionárias Alpha, matriz, na cidade de Novo Hamburgo (RS). Realizou-se um estudo de caso qualitativo na rede de concessionárias Alpha, em Novo Hamburgo, por meio de entrevistas com os gestores da área de CRM, Marketing e Vendas, bem como a análise de documentos e pesquisas disponibilizados pela empresa. Os resultados obtidos possibilitaram evidenciar que a utilização de ferramentas e estratégias de Marketing de Relacionamento e CRM permite uma melhor gestão das informações e a elaboração de estratégias para o aumento da satisfação, retenção e fidelização dos clientes, conforme a teoria pressupõe. Para pesquisas futuras, sugere-se o aprofundamento do tema, buscando maior compreensão das percepções e atitudes intrínsecas dos clientes com uma abordagem no âmago qualitativo da fidelização.

Palavras-chave: Marketing de Relacionamento; CRM (Customer Relationship Management); Valor; Satisfação; Lealdade.

\footnotetext{
${ }^{1}$ Bacharel em Administração de empresas pela Faculdade Monteiro Lobato (FATO). E-mail: guilherme_olkoski@ hotmail.com.

2 Professora da FATO, consultora de empresas e mestranda do Curso de pós-graduação da PUCRS. E-mail: reginauster@terra.com.br

${ }_{3}^{3}$ Professora da FATO e consultora de empresa. E-mail: licione@hotmail.com

${ }^{4}$ Professora da Faculdade da Serra Gaúcha (FSG) e integrante do grupo de pesquisa GEMAC (UNISINOS). E-mail: já.q.s@hotmail.com
} 


\begin{abstract}
As Brazilian market is a complex one, organizations with long-term vision to establish a lasting relationship with its customers searching for loyalty and increasing their profit per customer over time. Thus, this study wants to evaluate the results of the strategic management of customers through CRM (Customer Relationship Management) and Relationship Marketing at the network of concessionaires Alpha - Head Office Novo Hamburgo. It was made a qualitative study at Alpha network of dealerships in Novo Hamburg, through interviews with the managers of CRM, Marketing and Sales, as well as documents analysis and studies provided by the company. Results show that allowed the use of tools and strategies of Relationship Marketing and CRM allows better management of information and developing strategies to increase customer satisfaction, retention and loyalty as possible as the theory assumes. For future searchs suggests the deepening of the subject seeking greater understanding of the intrinsic perceptions and attitudes of customers with a qualitative approach at the heart of loyalty.
\end{abstract}

Keywords: Relationship Marketing; CRM (Customer Relationship Management); Value; Satisfaction; Loyalty.

\title{
1 Introdução
}

Uma empresa é um sistema aberto que interage com o meio no qual está inserido, meio este composto por funcionários, clientes, parceiros, fornecedores etc. Esta interação é suportada por uma rede de processos articulados, em que os canais de comunicação existentes dentro da empresa e entre esta e o seu meio envolvente são irrigados por informação. Para isso, cada vez mais as empresas vêm buscando formas de administrar e de obter competitividade na busca da maximização dos resultados e na gestão de relacionamento com seus clientes. Dentro desse contexto, emerge do Marketing o conceito de gestão estratégica de relacionamento e gestão de clientes, desenvolvendo um novo paradigma em relação à lealdade e à gestão do relacionamento com o cliente, orientado pelo marketing do relacionamento.

O marketing de relacionamento tem recebido, gradativamente, maior atenção dos gestores de pequenas, médias e grandes empresas. Com o objetivo de reter os clientes através da oferta de serviços de qualidade (BERRY, 1983; GRONRÖOS, 1990; GUMMESSON, 1993). O marketing de relacionamento permite aos gestores um melhor conhecimento de quem é o seu cliente, do que ele realmente gosta e o que fazer pare deixá-lo sempre satisfeito, fazendo, até mesmo, com que o cliente se sinta parte da empresa, gerando, portanto, sentimentos de comprometimento, lealdade e satisfação. Diante de um mercado cada vez mais competitivo, no qual empresas do mesmo ramo de atividade oferecem serviços cada vez mais parecidos, investir em um diferencial é gerar competência que permite se destacar dos concorrentes, e é com este foco que o marketing de relacionamento ganha fundamental importância.

Dessa forma, este estudo busca analisar a importância da gestão do relacionamento com os clientes, aliado ao Customer Relationship Management (CRM) para eficácia e efetividade das estratégias de marketing de relacionamento.

\section{Marketing de relacionamento}

O marketing de relacionamento, na prática de negócio e como um foco da pesquisa acadêmica, teve seu crescimento explosivo na década passada (SRINIVASAN e MOORMAN, 2005). A partir deste momento, tem tido maior atenção dos profissionais de marketing para

Rev. Adm. UFSM, Santa Maria, v. 2, n. 3, p. 417-432, set./dez. 2009 
qualquer tipo de empresa, seja ela de pequeno, médio e grande porte, tendo visão cada vez mais voltada para o cliente e em como satisfazê-lo, tornando-o fiel. Com esta finalidade, os profissionais do marketing utilizam estratégias para fortalecer os laços de relacionamento, permitindo que o ciclo de vida do cliente na empresa seja prolongado.

Marketing de Relacionamento são todas as atividades direcionadas através do desenvolvimento e manutenção de trocas relacionais bem-sucedidas e pode ser aplicado em diferentes contextos, podendo ter uma variedade de efeitos (MORGAN e HUNT, 1994). O foco do marketing de relacionamento tem como principais características a retenção do consumidor a um longo prazo, satisfação mútua, criar valor, prioridade da oferta de serviço de qualidade para consumidor, frequente contato, compromisso e interação caracterizada pela cooperação, confiança, respeito e segurança mútua. Seu gerenciamento envolve vários stakeholders, incluindo funcionários, parceiros e clientes, mantendo os clientes já existentes (FERREL e HARTLINE, 2005). Refere-se a todas as atividades de marketing direcionadas para estabelecer, atrair, desenvolver, manter e reter trocas relacionais bem-sucedidas (BERRY e PARASURAMAN, 1991; DWYER, SCHURR e OH, 1987). Marketing de Relacionamento é baseado na premissa da construção de um forte relacionamento que influencia positivamente no resultado das trocas. Segundo alguns pesquisadores, as trocas variam de um aspecto transacional para relacional (ANDERSON e NARUS, 1991). Alguns autores abordam que, em certas situações, o marketing de relacionamento tem um impacto negativo na performance da empresa (DE WULF, ODEKERKEN-SCHRÖDER e IACOBUCCI, 2001; HIBBARD KUMAR e STERN, 2001).

Berry (1983) descreveu cinco elementos estratégicos para praticar o marketing de relacionamento, que são: (a) desenvolver o serviço em torno da construção do relacionamento com o cliente; (b) customizar o relacionamento individual com cada cliente; (c) multiplicar o serviço com benefícios extras; (d) vender um serviço que encoraje a lealdade do cliente e (e) fazer marketing com os empregados para que eles atendam bem aos clientes.

O marketing de relacionamento é fruto de uma pluralidade de constructos (NETO, 2003). Morgan e Hunt (1994) destacam que a confiança, o comprometimento, a satisfação e a qualidade são mediadores do relacionamento e que trabalhar estes mediadores resulta em expectativa de continuidade da relação, lealdade do consumidor e boca a boca positivo. O cliente percebe valor no relacionamento quando recebe algum benefício com este relacionamento, aumentando a voluntariedade de desenvolver as relações; para isso, devese aumentar a lealdade; mas a lealdade pode ser definida e operacionalizada por diversos caminhos (MORGAN e HUNT, 1994).

O processo de construção do relacionamento é moldado, fundamentalmente, por um número de conteúdos relacionais básicos: econômicos, recursos e interação social, os quais atuam com antecedentes das resultantes dos relacionamentos (CRUTCHFIELD, 1998). O marketing de relacionamento pode ser visto como uma filosofia de negócios para o sucesso da empresa ou uma cultura organizacional distinta, que tem o relacionamento entre clienteempresa como o centro da estratégia dos negócios.

O marketing de relacionamento é um dos temas mais debatidos por profissionais da área de Marketing em todo o mundo. Essa filosofia de criar e manter relacionamento de longo prazo torna-se mais econômico e mais rentável do que a prática de marketing de massa, que usa estratégias para atrair clientes e não busca a retenção deles (VAVRA, 1993; LEWIS, 1997).

O Marketing de Relacionamento é um marketing que se baseia em interações dentro de uma rede de relacionamentos, seja a rede entre grupos de clientes com empresa (B2C), empresas com empresas (B2B) ou até mesmo clientes individuais com empresa (O2O) (GUMMESSON, 2005; LEWIS, 1997). 


\subsection{Customer Relationship Management (CRM)}

Atualmente, o conceito de CRM confunde-se com o de Marketing de Relacionamento, em razão de alguns autores intitularem o próprio Marketing de Relacionamento como CRM. O CRM é, essencialmente, a infraestrutura para se praticar o Marketing de Relacionamento, de maneira que ele se desenvolva dentro de um plano estratégico de marketing, sendo parte fundamental de todo o processo de gestão de relacionamento com clientes (ZENONE, 2007). Para Gummeson (2005), CRM são essencialmente os valores e estratégias do Marketing de Relacionamento que se transformam em aplicações práticas no decorrer de seu desenvolvimento, que pode ser generalizado e praticado por qualquer tipo de empresa e todos os tipos de ofertas, desde que essas sejam especificadas e estejam dentro do planejamento estratégico da organização.

De acordo com Batista (2006), o CRM é uma arquitetura que combina estratégias empresariais e tecnologia. Esta arquitetura busca entender os clientes de uma empresa, tendo como objetivo principal proporcionar vendas casadas e mensagens direcionadas a cada cliente de forma individual. Isso faz com que o faturamento da empresa aumente por meio da satisfação e retenção de clientes, bem como o baixo custo para adquirir e manter o cliente fiel. Praticar Marketing de Relacionamento com o auxílio de um CRM é fundamental para toda e qualquer organização, que busca aumento de lucratividade e competitividade no mercado em que atua. Devido à globalização, os consumidores deste século estão cada vez mais beminformados sobre o que querem, e é através de estratégias de CRM atreladas ao Marketing de Relacionamento que se pode agregar valor para o cliente buscando sua fidelização (PEPPERS e ROGERS, 2001). Estratégias de CRM são cada vez mais frequentes nesse novo cenário em que vivemos. Estima-se que conquistar um cliente novo chega a custar até dez vezes mais do que mantê-lo fiel, usando estratégias e campanhas de CRM e Marketing de Relacionamento, conforme Batista (2006).

A relação lucro versus investimento de clientes pode ser entendida da seguinte maneira: com o passar do tempo, quanto mais a empresa gasta com aquisição de novos clientes, mais ela irá gastar porque, na maioria das vezes, o cliente só efetua uma compra sem valor agregado algum para ele. Já na filosofia do Marketing de Relacionamento, quanto mais é investido no relacionamento com o cliente, mais ele gera lucro para a organização, efetuando compras com margens maiores, porque ele é um cliente que reconhece o valor que a empresa lhe fornece, tornando-se, assim, um cliente fiel (BATISTA, 2006; PEPPERS e ROGERS, 2001; GREENBERG, 2001).

Na busca da fidelização de clientes, a utilização de sistemas de CRM permite que as empresas respondam a perguntas como (BATISTA, 2006): Quais são as minhas características de mercado? Qual é o perfil individual dos clientes? Quais são os hábitos de consumo de grupos específicos? Quais clientes são ou poderão ser fiéis e lucrativos? Quais são as taxas de retorno das minhas campanhas publicitárias? Qual é a maneira mais eficiente de atingir meus consumidores? Quais mensagens? Quais canais? Que partes do meu site meus clientes visitam? Onde devo anunciar?

O CRM deve ser visto pelas organizações como uma possibilidade de tornar oportunidades em negócios através de uma comunicação integrada, com seus clientes e toda a cadeia de valor, comunicando-se adequadamente, em tempo real, gerando um aumento nas vendas, fidelizando os clientes e evitando perda de parceiros de negócios (BRETZKE, 2000; BROWN, 2001). Dentro do contexto de CRM, existem vários sistemas que dão suporte a todo esse processo de gestão de relacionamento com clientes. Deste modo, essa estratégia de CRM 
é dividida em três tipos distintos, que se baseiam em colaboração, operação e análise, visando à integração de todas as informações sobre clientes, para uma melhor tomada de decisão dentro do contexto do marketing de relacionamento (BATISTA, 2006; PEPPERS e ROGERS, 2001; REINARES, 2007).

A integração de sistemas nas estratégias de CRM permite a melhoria da qualidade das informações. Sistemas de informação integrados automatizam processos de comunicação e transição de informações dentro da organização, dando mais facilidade nas interações com clientes e parceiros, permitindo vendas cruzadas com personalização de produtos/serviços, possibilitando sempre a melhoria desses processos por meio de feedback contínuo (BATISTA, 2006; PEPPERS e ROGERS, 2001; REINARES, 2007).

CRM operacional é toda aplicação de tecnologia da informação (TI), que visa a melhorar a eficiência entre o relacionamento do cliente com a empresa. É nele que a maioria das empresas que pratica o CRM está direcionada e envolve uma série de sistemas básicos que auxiliam na interação com os clientes. Está entre as características de CRM operacional a automação da força de vendas (SFA), automação dos canais de vendas (SCA), dos sistemas de comércio e dos call-centers (BATISTA, 2006; PEPPERS e ROGERS, 2001; ZENONE, 2007). Já o CRM colaborativo é a aplicação de TI que permite a automação dos diversos pontos de contato que o cliente tem com a empresa. Esses pontos devem estar preparados para dar suporte e interagir com os clientes para abastecer com informações o sistema de banco de dados do CRM operacional. Estão inseridas no CRM colaborativo as formas convencionais de comunicação direta ou indireta com os clientes que a organização utiliza, que pode ser representado pelo telefone, fax, carta, e-mail, website, face a face, ouvidoria e serviços de atendimento ao consumidor. No CRM analítico, é realizada a análise dos dados coletados. Essa parte possibilita determinar quais são os clientes da empresa que devem ser tratados de forma diferente. O CRM analítico é a inteligência de todo o processo, desde a identificação do cliente até a personalização dos produtos/serviço para ele (BATISTA, 2006; PEPPERS; ROGERS, 2001; ZENONE, 2007).

\section{Valor percebido e satisfação}

Valor, para o cliente, significa todo o conjunto de benefícios que a empresa promete entregar; é algo mais que o posicionamento central da oferta em si; é o valor agregado que a empresa pode oferecer para o cliente. Se a promessa de entrega de valor será ou não atendida, dependerá somente da capacidade da empresa (KOTLER e KELLER, 2006). Entregar valor superior ao cliente conduz a organização a lucros maiores no futuro com o mesmo cliente. Os consumidores que recebem valor superior agregado têm grandes possibilidades de realizarem novas compras com margens maiores para a organização (GALE, 1996). Para Teixeira (2006), o valor caracteriza-se por três aspectos que contribuem para o desenvolvimento da troca, sendo eles: (a) o valor é sempre perceptivo, variando conforme a percepção individual de compra de cada consumidor; (b) o valor é contextual, variando conforme a situação de compra e as alternativas disponíveis e (c) o valor é multidimensional, uma vez que os clientes avaliam os benefícios recebidos em termos econômicos, técnico-funcionais e psicológicos.

O processo de estabelecer e colocar valor na hora da troca implica o conhecimento de cada segmento de clientes que a organização possui, tornando necessário um planejamento de como entregar o valor aos clientes e de qual forma convencê-los a realizarem a troca (compra) com a empresa. Por esse motivo, a venda de valor torna-se o grande desafio do Marketing (TEIXEIRA, 2006). 
O consumidor comprará da empresa que lhe entregar maior valor, sendo que o valor entregue ao consumidor é a diferença entre o que ele espera do produto ou serviço com o que ele pode pagar por ele. O cliente que recebe maior benefício na compra de um produto com custo relativamente padrão ficará encantado e poderá realizar uma recompra, cabendo à empresa gerir o "cuidar" desse cliente através das estratégias de Marketing de Relacionamento e CRM (KOTLER, 2000; DOMINGUEZ, 2000).

Vavra (1993) diz que é possível conhecer as necessidades e alocá-las de acordo com a perspectiva do cliente, buscando criar um alto valor e tentando satisfazê-lo. Os profissionais de marketing devem saber que um cliente, ao buscar a organização para realizar uma compra, vem com uma perspectiva de construção de relacionamento e, sabendo as necessidades dos clientes e aproveitando-se dessa perspectiva, pode-se construir uma relação duradoura e de alto valor, tanto para o cliente quanto para a empresa, haja vista as estratégias de Marketing de Relacionamento e CRM citadas anteriormente.

O conhecimento que uma empresa precisa ter sobre seu consumidor é, em princípio, o primeiro passo na criação de valor para gerar a satisfação do cliente. Conhecer a sua perspectiva e o que ele busca com o maior grau de detalhamento possível, bem como sua família, seus costumes e seus relacionamentos interpessoais é de fundamental importância para qualquer organização cujo foco esteja em clientes (GIGLIO, 2003; KARSAKLIAN, 2004). É através da entrega de valor que se pode chegar à satisfação, que, por sua vez, é compreendida como um resultado do valor percebido e das expectativas atendidas e entregues ao consumidor final. Se a empresa conseguir atingir as expectativas de seu consumidor, ela terá um cliente satisfeito; se ela não atingir essas expectativas, o cliente estará insatisfeito (ENGEL, BLACKWELL e MINIARD, 1999).

A satisfação está ligada ao valor percebido pelo cliente em relação ao produto ou serviço que lhe foi entregue, mas, segundo Gale (1996), para se chegar a um nível de encantamento, as empresas precisam migrar da satisfação de clientes para um paradigma de valor percebido pelo cliente. Desse modo, as empresas podem aumentar a fidelidade de seus clientes buscando a sua retenção. Portanto, a satisfação é o primeiro passo para se buscar a fidelização do cliente, sendo que só é possível deixar um cliente satisfeito entregando-lhe um alto valor naquilo que ele procura. Por isso, entender sua percepção de compra torna-se tão importante; sabendo do perfil do cliente, a empresa pode direcionar seus esforços para um determinado grupo ou, até mesmo, para um cliente individual, personalizando, assim, seus produtos/serviços, buscando seu encantamento e sua fidelização (BRETZKE, 2000; GREENBERG, 2001).

\section{Lealdade e fidelidade}

Conforme Reichheld (1996), um consumidor leal mantém uma atitude favorável em relação ao produto ou serviço que adquirirá, implicando compras repetitivas, baseadas em fatores cognitivos, que são os componentes clássicos da atitude do consumidor contemporâneo que as empresas encontram no mercado atualmente. A fidelidade tem esse mesmo conceito, embora abranja também todo o processo aplicado para a busca e a retenção de clientes, desde o primeiro contato com a empresa até a entrega do produto/serviço ao cliente, com qualidade e valor superior ao que ele espera (BORBA, 2004). No entanto, com freqüência, essas duas expressões têm sido usadas como sinônimos ${ }^{5}$ (SANTOS e FERNADES, 2008; PEPPERS e ROGERS, 2001; REICHHELD, 1996).

\footnotetext{
${ }^{5}$ Neste artigo, toma-se lealdade como sinônimo de fidelidade.
} 
Mas como definir fidelidade? Fidelidade é descrita como um estado mental, um conjunto de atitudes, crenças e desejos que leva um consumidor a continuar efetuando compras com uma empresa. Stone e Woodcock (1998) ressaltam que a fidelidade é um estado mental relativo, ela impede a lealdade a outros fornecedores, mas não a todos, na medida em que um cliente poderia ser leal a mais de um fornecedor concorrente. Pode-se tomar como exemplo os programas de fidelidade. Nesses programas, o grande objetivo é a compra repetitiva, com margens maiores para a organização. Programas de fidelização são muito utilizados por administradoras de cartão de crédito e empresas aéreas, que personalizam seus serviços/ produtos de tal maneira que o cliente consiga perceber um alto valor em continuar a fazer negócios com ela, influenciando o comportamento de compra de outros clientes e trazendoos para sua empresa, aumentando o market-share dessa organização, que lhe proporcione um encantamento nos serviços/produtos prestados (DIAS et al., 2004; PEPPERS e ROGERS, 2001; BRETZKE, 2000; GREENBERG, 2001).

Reichheld (1996) assevera que não se pode fidelizar clientes sem entregar-lhes algo em troca que não seja somente o produto ou serviço; por isso é necessário que as empresas conquistem sua lealdade, porque o consumidor só investirá seu tempo e dinheiro de forma leal se ele acreditar que sua contribuição para a empresa lhe gerará um retorno superior e criará valor ao longo do seu ciclo de vida como cliente daquela organização.

O valor percebido e a satisfação estão ligados à lealdade e à fidelidade como causa e efeito. Isso se deve ao fato de que a lealdade inicia uma série de efeitos econômicos, como o aumento da fatia de mercado de clientes de maior valor para a organização, executando compras repetidas e crescimento sustentável da empresa, proporcionando que esta entregue um valor superior aos seus clientes. Como efeito disso, a lealdade pode vir a ser uma medida de confiança para saber se a empresa realmente entrega valor superior aos seus clientes, uma vez que a lealdade proporciona crescimento, lucro e maior valor agregado para ambos, cliente e organização (REICHHELD, 1996; BRETZKE, 2000; GREENBERG, 2001).

A fidelização nasce do relacionamento constante com os clientes através de estratégias de Marketing de Relacionamento, já mencionadas anteriormente, e CRM. O grande desafio da fidelização é o ato de mensurá-la. Para alcançar tal feito, os profissionais de Marketing precisam determinar como os clientes percebem os produtos/serviços e o valor de suas transações. Isso pode ser feito por meio de pesquisa de satisfação, pesquisa de percepção, de valor, de intenção de recompra, observando também o lado emocional do cliente e através do feedback do cliente a respeito do produto/serviço prestado, tendo como suporte todas as informações dos clientes nas ferramentas de CRM da organização (DIAS et al., 2004; BRETZKE, 2000; GREENBERG, 2001).

A fidelização é o grande objetivo das empresas que praticam o Marketing de Relacionamento voltado para o valor ao cliente. A grande vantagem da fidelização é a lealdade que o consumidor tem com a marca e a repetição de compra devido ao alto valor percebido por ele nos produtos/serviços que a "sua" empresa oferece; isso porque clientes fiéis não apenas voltam a comprar, mas defendem produtos e serviços junto aos seus amigos, prestam menos atenção às marcas concorrentes e, frequentemente, compram extensões de linhas de produtos/ serviços, gerando mais lucros para a empresa (BRETZKE, 2000; GREENBERG, 2001).

Sendo assim, constata-se a importância da mudança de paradigma em relação ao novo conceito de Marketing que emerge no mercado atualmente. A mudança desse paradigma reflete diretamente nas ações dentro do planejamento de Marketing das organizações que, para obter competitividade estratégica e melhor posicionamento no mercado, estão visando, cada vez mais, um relacionamento com o seu público de interesse, buscando a melhoria de gestão do relacionamento e fidelização com seus clientes. 


\section{Método}

A pesquisa realizada foi de natureza qualitativa, com delineamento descritivoexploratório, através de um estudo de caso que, conforme Yin (2005), permite preservar as características dos acontecimentos nos processos administrativos e organizacionais nas empresas. Para Candeloro e Santos (2006), o estudo de caso ocorre por meio do levantamento de dados, uma vez que ele descreve os fatos observados na área da gestão administrativa, relatando seus componentes constituintes e analisando-os. Para as autoras, essa técnica é a que mais se alia à pesquisa de natureza qualitativa, contemplando fenômenos sociais contemporâneos. Os sujeitos da pesquisa foram escolhidos de forma intencional não-probabilística, sendo: um gestor da área de CRM e Marketing digital, um gerente do núcleo de relacionamento, um gerente da área de vendas e um gerente da área de pós-venda da empresa pesquisada. As técnicas de coleta de dados foram a entrevista em profundidade, com roteiro semiestruturado composto por perguntas abertas. Essas entrevistas foram levadas a efeito entre setembro e outubro de 2008. Além disso, utilizou-se a pesquisa documental, a qual, segundo Forster (apud ROESCH, 1995), indica que os documentos possuem importância própria, a partir do momento que representam, de forma palpável, a organização, seus sistemas e estruturas.

A parte documental foi cedida pela empresa pesquisada, para a análise da fidelização dos seus clientes. Foram analisados dados que correspondem ao índice de nível de satisfação em relação aos serviços prestados e ao índice de satisfação em relação à compra de automóvel, bem como às entrevistas dos gestores citados anteriormente. Sendo assim, fica registrado que não foi aplicado nenhum tipo de questionário direto aos clientes da organização, uma vez que a organização realizava este tipo de pesquisa.

O tratamento dos dados qualitativos foi realizado por meio da técnica de Análise de Conteúdo, que, segundo Bardin (1995, p. 31), é "[...] um conjunto de técnicas de análises das comunicações. Não se trata de um instrumento, mas de um leque de apetrechos". As técnicas utilizadas para garantir a validade e fidedignidade do estudo foram fundamentais. Para tanto, realizou-se a triangulação de dados e de instrumento de coleta de dados, sendo que os respectivos entrevistados foram questionados, posteriormente, sobre os dados que foram selecionados para incorporar o estudo.

\section{Análise dos dados}

Na Empresa Alpha ${ }^{6}$, utiliza-se o CRM para a gestão de clientes desde 2003. Mas a empresa, segundo o gestor de CRM e Marketing digital, "trabalha com a gestão de informações sobre seus clientes desde 1993" e tem amplo conhecimento e domínio da ferramenta, que é considerada "uma ferramenta fabulosa para a gestão de clientes". Segundo Zenone (2007) e Peppers e Rogers (2001), a ferramenta de TI, que é o CRM, é totalmente direcionada para a gestão do relacionamento com clientes através de um conjunto de estratégias que, de acordo com os objetivos empresariais das organizações, permita uma maior eficiência e eficácia na gestão das informações sobre seus clientes.

O departamento de Tecnologia da Informação (TI) da empresa tem uma participação ativa no desenvolvimento de estratégias de CRM, sendo, de acordo com o gestor de CRM e Marketing digital na Alpha, "de fundamental importância porque ela está voltada ao suporte de

\footnotetext{
${ }^{6}$ Neste trabalho, manter-se-á anonimato da empresa em estudo, uma vez que foi condição sine qua non colocada pela própria empresa para a realização da pesquisa.
} 
todo nosso banco de dados e é a principal responsável pela integração dos nossos programas voltados a gestão das informações dos nossos clientes".

Para esse gestor, "a TI na Alpha sempre esteve voltada para a manutenção, sendo responsável pelo funcionamento desse banco de dados para que possamos utilizar esses dados com maior confiabilidade".

Sendo assim, o gestor de CRM e Marketing Digital da empresa pesquisada relata que "o CRM permite que a Alpha possa direcionar seus esforços para determinados grupos de clientes de uma maneira precisa em conjunto com estratégias de relacionamento com os clientes, permitindo-nos dar um tiro certeiro no nosso cliente, fazendo que ele se sinta encorajado para realizar a compra conosco". De acordo com Peppers e Rogers (2001), Brown (2001), Zenone (2007) e Gummesson (2005), o CRM não é um conceito e nem um projeto: é uma estratégia de negócio, uma filosofia plenamente voltada ao entendimento e à antecipação das necessidades dos clientes atuais e potenciais. CRM é, essencialmente, os valores e estratégias do Marketing de Relacionamento, que se transformam em aplicações práticas no decorrer de seu desenvolvimento, sendo que é através de estratégias de CRM atreladas ao Marketing de Relacionamento que se pode atingir o cliente, a fim de incentivá-lo para a realização da compra, buscando o seu encantamento e sua retenção. Brown (2001) destaca que, na sua simples forma, CRM provê uma visão unificada da relação com o cliente através de toda a empresa.

Para atingir o cliente de maneira correta, a Alpha busca captar as informações de seus clientes de várias maneiras. Conforme o gestor de CRM e Marketing digital:

existem três formas de fazermos a coleta de dados dos nossos clientes: através do departamento de Peças, de Vendas e de Tele-marketing. Sendo assim, em todos os momentos da verdade nós podemos fazer essa coleta de dados. Ainda assim, nós encorajamos os vendedores a fazer o possível para pegar o maior número de informação dos nossos clientes, pois eles também têm a responsabilidade de alimentar o nosso banco de dados.

Nota-se, pelo depoimento, o comprometimento na busca do conhecimento do cliente. Segundo o gestor, "Na Alpha, o CRM trabalha em conjunto com um ERP”. Isso significa que nossos sistemas estão atrelados e trabalhando em conjunto para a melhor gestão dessas informações, que ficam disponíveis para todos os pontos de contato do cliente com a empresa". Verifica-se que a Alpha tem um processo de gestão de informações integrado sobre clientes, e essas informações são compartilhadas com outro software, que permite que elas circulem por toda a empresa, corroborando com a lista de benefícios apresentados por Oliveira (2002).

Observe-se que a empresa faz a análise dos dados de seus clientes (CRM Analítico) no seu departamento de marketing em conjunto com o de CRM. Esses dados são repassados aos vendedores e para toda a empresa, por meio de um software, chamado de ERP, que alimenta os sistemas (softwares) de força de vendas da empresa (CRM Operacional). Por sua vez, os vendedores usam esses dados para interagir com seus clientes de diversas formas, desde um telefonema, conforme o follow-up da empresa, ou até mesmo através de uma página na Web (CRM Colaborativo) para realizar uma venda ou prestar um serviço com qualidade.

\footnotetext{
${ }^{7}$ Enterprise Resource Planning, ver Laudon e Laudon (1999).
} 
Para corroborar esse fato, o gestor de CRM e marketing digital relata um exemplo de todo o processo:

se um cliente vem até nós e nosso vendedor não conseguiu realizar a venda, no dia seguinte nosso follow-up entra em contato com o cliente para verificar porque não foi fechado o negócio e o que podemos fazer para que ele possa vir a fechar o negócio conosco. Fazemos isso porque sabemos que quando um cliente vai para uma concessionária para realizar a compra de um carro e ele não realiza, ele vai comprar um outro carro em no máximo sete dias, então o Marketing e o CRM nos permite ter essa visão, fazendo com que possamos dirigir todos nossos esforços para realizar o negócio com o cliente.

De acordo com a revisão da literatura, o CRM é utilizado como uma extensão das estratégias de Marketing de Relacionamento, e essa ferramenta tecnológica, atrelada com os objetivos estratégicos da organização, permite uma visão total com foco no cliente, a fim de satisfazer suas necessidades e atender seus desejos, para que volte a negociar com a empresa. Segundo o gestor de CRM e Marketing digital:

o grande objetivo do CRM na Alpha é dar um tiro certeiro no nosso cliente, ou seja, quando um cliente entra na Alpha, nós estamos preparados para poder, de algum modo, efetuar a venda de um veículo ou oferecer um serviço com alto valor agregado para nosso cliente, fazendo com que ele volte a fazer negócios conosco.

Esse depoimento caracteriza a recompra. Percebe-se que existe, na Alpha, a preocupação com a retenção de clientes, o que, via de regra, torna-se mais vantajoso para a organização a adoção desse tipo de estratégia. A meta do CRM é a máxima satisfação do consumidor e, ao invés de conquistar novos clientes, objetiva manter os clientes já existentes através da criação do capital de relacionamento, que envolve compromisso, confiança, interdependência e cooperação (STRAUSS, EL-ANSARY e FROST, 2003). Em função disso, o cliente percebe a importância dele no relacionamento de compra com a empresa que utiliza ferramentas como o CRM para gerir seus negócios. Conforme o gestor de CRM e Marketing digital, "os clientes da Alpha percebem o valor que nós transmitimos a ele, e ele se importa muito com esse valor, com essa qualidade nos serviços prestados".

O grande objetivo do Marketing de Relacionamento, segundo Vavra (1993) e Lewis (1997), é criar e manter um relacionamento de longo prazo com os clientes; em função disso, essa prática torna-se mais econômica e rentável do que a prática de marketing de massa, que usa estratégias para atrair clientes e não para retê-los.

A exemplo disso, a empresa objeto de estudo, Alpha, desenvolve relacionamento com seus clientes e usa um software de gestão de clientes, como visto anteriormente. Segundo o gestor de CRM e Marketing digital, "o CRM, aqui na Alpha, dá todo o suporte necessário para empregarmos as estratégias de relacionamento voltadas para nossos clientes". Para o gerente do núcleo de relacionamento da Alpha:

a preocupação da empresa com o relacionamento com seus clientes é enorme, por isso é desenvolvido periodicamente ações para conseguirmos manter sempre um contato periódico com nossos clientes e também para nos mantermos atualizados sobre como anda nosso produto que está em sua posse, assim nós conseguimos sempre oferecer a ele um serviço ou um produto que se complementa com o seu automóvel.

Rev. Adm. UFSM, Santa Maria, v. 2, n. 3, p. 417-432, set./dez. 2009 
A Alpha consegue manter uma base de dados excepcional em relação a seus clientes. Para corroborar essa idéia, o depoimento a seguir relata detalhadamente como a Alpha consegue mapear as informações e direcioná-las para manter um relacionamento com seus clientes. Segundo o gestor de CRM e Marketing Digital,

\begin{abstract}
de acordo com os dados da Alpha, sabemos que um cliente troca de carro, em média, a cada dois anos. Sendo assim, a cada seis meses temos que manter contato com nossos clientes para avisar a eles a respeito das revisões. Ainda assim, sabemos que a cada três meses ele precisa de algum outro tipo de serviço esporádico. Em função disso, nossos esforços sempre estão direcionados para tentar agregar um alto valor nos serviços que prestamos aos nossos clientes. Se nós fizermos isso com qualidade, temos a certeza que no final dos dois anos ele realizará a recompra do seu automóvel com a gente.
\end{abstract}

Para Vavra (1993), o processo de conhecimento dos clientes começa desde o primeiro contato do cliente com a empresa, e cabe à organização gerir todas as informações obtidas dos clientes para garantir a sua completa satisfação no processo de compra. Segundo Zenone (2007), as empresas buscam todas as informações sobre seus clientes, visando a zelar e a manter um relacionamento duradouro de maneira a produzir um conhecimento profundo do cliente, podendo constituir, assim, uma arma eficaz a serviço da competitividade estratégica da organização. Na empresa objeto de estudo, pode-se observar a preocupação em relação a esse aspecto, conforme o relato do gerente de vendas, que garante:

\begin{abstract}
na Alpha, o cliente chega e é atendido por uma recepcionista que tem acesso ao nosso sistema de gestão, onde ela consegue identificar as primeiras necessidades dele tipo: veículo de interesse; mídia de atração; preferência de vendedor e até a obtenção dos dados cadastrais do cliente. Depois disso, ela encaminha o cliente para o vendedor, onde o cliente é tratado com total atenção e é oferecido a ele a melhor solução para a obtenção do seu desejo, o carro. Após, o cliente faz um test-drive e Ihe é apresentada a proposta final de negócio. É feito um acompanhamento do cliente com a venda, sendo concretizada ou não, através de follow-up de venda, pesquisa de satisfação e contatos de manutenção para termos um feedback do serviço prestado a ele, buscando sempre a melhoria contínua desses serviços.
\end{abstract}

Observa-se que, desde o primeiro contato, o cliente já tem total atenção e suporte para que se sinta confortável e favoravelmente inclinado para a realização da compra. Verificando isso, o gerente de vendas da empresa pesquisada relata que "o sistema de gestão de clientes aqui da Alpha proporciona as informações de todos os contatos e quem atende o cliente tem acesso a essas informações diretamente e de forma completa", o que é um fator preponderante para as organizações que queiram manter um relacionamento de longo prazo com seus clientes.

A Alpha segue uma filosofia de atendimento que, segundo o gerente de vendas e o gerente de pós-vendas da empresa, "buscamos sempre a satisfação do cliente, mais que isso; tentamos encantá-lo, escutando-o e suprindo suas necessidades e desejos". Para a empresa objeto de estudo, o relacionamento começa no momento do atendimento, sendo que "é mantido o mesmo padrão de atendimento para todos os clientes da empresa, seja ele um cliente em potencial ou um cliente que vem até nós para realizar um serviço em nossa concessionária".

No pós-venda, considerada pela Alpha um fator decisivo na fidelização dos seus clientes, o atendimento é realizado da forma mais personalizada possível, sendo que, segundo o relato do gerente de pós-venda, "A Alpha contata o cliente para o agendamento do serviço. 
O cliente é recebido diretamente pelo técnico que vai executar o serviço e passar os resultados depois, gerando mais confiança"

Segundo o gestor de CRM e Marketing Digital, "o Marketing de Relacionamento e o CRM nos permite uma visão abrangente de todos nossos clientes, a partir daí podemos direcionar ações para determinados grupos de clientes". Peppers, Rogers e Dorf (2001) afirmam que empresas que se utilizam de estratégias de Marketing de Relacionamento para se manterem competitivas no mercado têm um único foco: o cliente. Para essas empresas, o seu maior bem é o seu cliente. Segundo o gerente do núcleo de relacionamento da Alpha, "Os clientes são o centro de nossa atenção. Com a concorrência cada vez mais acirrada, o relacionamento com o cliente é um grande diferencial e buscamos sempre realizar diversas ações e projetos nesse âmbito".

Na Alpha, existe um departamento especializado para a pesquisa e a avaliação da satisfação dos clientes. Todos os clientes que realizam algum serviço na concessionária ou que compram um carro são contatados pela empresa e são ouvidos para saber como foi o atendimento; como foi o andamento das negociações; a satisfação em relação aos serviços prestados pela concessionária. Essa pesquisa é intitulada na empresa como Sistema de Medição Semanal de Satisfação (SMS). Segundo o gerente do núcleo de relacionamento da Alpha,

\begin{abstract}
o SMS é um item de verificação do ISC - Indicador de Satisfação do Cliente. O ISC é realizado pela General Motors e tem como objetivo contatar todos os clientes que compraram um carro novo conosco, para saber o índice de satisfação desse cliente em relação ao processo de compra. O ISC é usado pela GM para nos avaliar, pois a Alpha tem a representação da marca Chevrolet e é através desse indicador que a GM sabe se nossos clientes estão ou não satisfeitos com nossos serviços.
\end{abstract}

O SMS é realizado semanalmente pela empresa, e ele emite relatórios periódicos mensalmente para a análise estratégica do índice de satisfação dos clientes. O SMS é mais abrangente que o ISC, visto que o SMS verifica todos os clientes que efetuaram um serviço ou realizaram a compra de um carro novo ou usado. Já o ISC, que é realizado pela GM, avalia somente o nível de satisfação do cliente que obteve um carro Chevrolet novo. Segundo o gerente do núcleo de relacionamento,

quando um cliente compra um carro na Alpha, dentro de, no máximo, 45 dias, a GM irá entrar em contato com ele para saber seu nível de satisfação e fazer o ISC. O SMS permite que a Alpha tenha esse feedback do cliente antes que a GM possa fazer a sua avaliação, fazendo com que a gente tenha uma resposta diretamente do cliente a respeito dos serviços que prestamos a ele, sem contar que com o SMS, nós conseguimos medir não só a satisfação do cliente que adquiriu um carro novo, mas sim de todos os clientes que executaram algum tipo de serviço aqui na Alpha.

Conforme dados fornecidos pela empresa objeto de estudo, o resultado da aplicação do SMS com seus clientes mostrou que, após pesquisa com todos os clientes que realizaram uma compra de veículo ou utilizaram os serviços da concessionária, o índice de clientes satisfeitos é de $94 \%$ plenamente satisfeitos, em maio de 2008, e, em outubro, essa percentagem aumentou para $98 \%$.

Segundo Gale (1996), a satisfação está ligada ao valor percebido pelo cliente em relação ao produto ou serviço que lhe foi entregue. Para Bretzke (2000) e Greenberg (2001), a satisfação é o primeiro passo para se buscar a fidelização do cliente, e só é possível deixar 
um cliente satisfeito entregando-Ihe um alto valor naquilo que ele procura. Em função disso, a Alpha trabalha para garantir que seus clientes se sintam membros da Alpha. O gestor de CRM e Marketing digital da empresa pesquisada relata:

estamos constantemente trabalhando para que nossos clientes se sintam fidelizados, se sintam parte da Alpha. O processo de fidelização se dá de acordo com o tempo e através de alguns aspectos que os clientes levam em conta na hora da utilização de serviços. Aqui na Alpha nós trabalhamos a fidelização ao longo da vida do cliente com nossa empresa.

A Alpha procura sempre agregar o máximo de valor nos seus produtos e serviços para que seus clientes percebam que é vantajoso manter um relacionamento com ela. Diante da análise, pode-se afirmar que a Alpha trabalha com foco no cliente, uma vez que os dados aqui analisados serviram para uma precisa verificação em relação aos objetivos da pesquisa. A seguir apresentar-se-ão as considerações finais acerca do estudo realizado.

\section{Considerações finais}

A informação nunca teve um valor tão grande, seja para a tomada de decisões estratégicas, seja para as atividades operacionais. Esse valor fica mais evidente quando se considera o aumento da lucratividade por cliente que é obtido com uma estratégia de relacionamento, além da redução nos custos operacionais, pela otimização do processo de administração do pedido (BRETZKE, 2000). Dessa forma, investir na filosofia de CRM ganha fundamental importância no meio organizacional, mas o projeto de CRM deve ser iniciado de forma gradual, sendo os resultados medidos e apresentados para toda a organização. Em médio e longo prazo, programas de marketing de relacionamento são auto-sustentados, uma vez que se economizam recursos com os clientes de baixo e nenhum valor e aplicam-se esses recursos nos clientes de alto valor.

A estratégia de CRM permite, fundamentalmente, enriquecer o relacionamento com os clientes, coletar informações sobre qualquer contato que ocorra por qualquer meio, em tempo real e, através da disseminação dessas informações, permite que o cliente seja conhecido e cuidado por todos na organização (HOUBRICH, 2002). Além disso, o marketing de massa pode aplicar um pouco de seu orçamento em estratégias de retenção, no momento em que trata de forma diferenciada os melhores clientes. Os resultados são a experiência positiva do consumidor, um melhor senso de lealdade e aumento do rendimento da companhia (SOWINSKI, 2000).

Não é de hoje que as empresas buscam maneiras mais eficientes e eficazes de se garantir no mercado. A globalização que assola o mundo trouxe consigo uma acirrada concorrência para o mercado brasileiro, sobretudo no mercado automobilístico, cujos clientes são muitos exigentes e informados e que a compra se caracteriza por alto envolvimento.

Sendo objetivo deste trabalho analisar a importância da filosofia do CRM para as estratégias de marketing de relacionamento, evidenciou-se que a empresa pesquisada emprega, na prática, estratégias de relacionamento com clientes e consegue atingir tal feito com o auxílio do CRM; isso proporciona à empresa um posicionamento estratégico e vital para os negócios da organização. Tais estratégias são disseminadas por toda empresa, provocando engajamento de todos os colaboradores de linha de frente, que trabalham diretamente com clientes, a buscar a satisfação total do cliente e a sua consequente retenção. 
Como limitadores do estudo, tem-se o fato de constituir-se de um Estudo de Caso, cujos resultados não podem ser generalizados para outras situações semelhantes, mas nada impede de ser replicado em outras empresas, de forma a buscar evidências que possam complementar, questionar ou aprofundar os resultados apresentados nesta pesquisa.

Sendo assim, o presente estudo sugere que pesquisas futuras façam o aprofundamento do tema com uma abordagem no âmago qualitativo da lealdade, buscando maior compreensão das percepções e atitudes intrínsecas do consumidor final, para se chegar, com mais eficácia, em um nível mensurável de satisfação e retenção dos clientes. 


\section{Referências}

ANDERSON, J.; NARUS, J. A model of distributor firm and manufacturer firm working partnership. Journal of marketing, v. 54, n. 1, jan. 1990.

BARDIN, L. Análise de conteúdo. Edições 70, 1995.

BATISTA, E. O. Sistemas de informação: o uso consciente da tecnologia para o gerenciamento. São Paulo: Saraiva, 2006.

BERRY, L. Relationship marketing: emerging perspectives of service marketing Chicago.

American Marketing Association, p. 25-28, 1983.

BERRY, L.; PARASURAMAN, A. Marketing services. New York: The Free, 1991.

BORBA, V. R. (Org.). Marketing de Relacionamento para organizações de saúde: fidelização de clientes e gestão de parcerias. São Paulo: Atlas, 2004.

BRETZKE, M. Marketing de relacionamento e competição em tempo real com CRM (Customer Relationship Management). São Paulo: Atlas, 2000.

BROWN, S. A. CRM - Customer Relationship

Management: uma ferramenta estratégica para o mundo e-business. Tradução de Juliana Machado Gorga. São Paulo: Makron Books, 2001.

CANDELORO, J. R.; SANTOS, V. dos. Trabalhos acadêmicos: uma orientação para a pesquisa e normas técnicas. Porto Alegre: AGE, 2006.

\section{CRUTCHFIELD, T. Customer retention in} consumer services: a multiple sources- multi commitments model of marketing relationships. Doctoral Dissertation, University of Alabama, 1998.

DE WULF, K.; ODEKERKEN-SCHRÖDER, G.; IACOBUCCI, D. Investments in consumer relationships: a cross-country and cross-industry exploration. Journal of Marketing, v. 65, p. 3350, Oct. 2001.
DIAS, S. R. et al. Gestão de marketing. São Paulo: Saraiva, 2006.

DOMINGUEZ, S. O valor percebido como elemento estratégico para obter a lealdade dos clientes. Caderno de Pesquisas em Administração, São Paulo, v.7, n. 4, out./dez. 2000.

DWYER, P.; SCHURR, H.; OH, S. Developing buyer-seller relationships. Journal of Marketing, v. 51, p. 11-27, Apr. 1987.

ENGEL, J. F.; BLACKWELL, R. D.; MINIARD, P. W. Comportamento do Consumidor. Tradução de Christina A. de Menezes. 8. ed. Rio de Janeiro: LTC, 1999.

FERREL, O. C.; HARTLINE, M. Estratégias de marketing. São Paulo: Pioneira Thomson Learning, 2005.

GALE, Bradley T. Gerenciando o valor do cliente: criando qualidade e serviços que os clientes podem ver. São Paulo: Pioneira, 1996.

GIGLIO, E. M. O Comportamento do consumidor. 2. ed. rev. ampl. São Paulo: Pioneira Thomson Learning, 2003.

GREENBERG, P. CRM - Customer Relationship Management na velocidade da luz: conquista e lealdade de clientes em tempo real na internet. Tradução de Reynaldo C. Marcondes. Rio de Janeiro: Campus, 2001.

GRÖNROOS, C. Relationship Approach to the Marketing Function in Service Contexts: the Marketing and Organization Behavior Interface. Journal of Business Research, n.1, 1990.

GUMMESON, E. Marketing de relacionamento total: gerenciamento de marketing, estratégia de relacionamento e abordagens de CRM para a economia de rede. Tradução de Marina Barbieri Campomar e Jonathan Hogan. 2. ed. Porto Alegre: Bookman, 2005.

HIBBARD, J. D.; KUMAR, N.; STERN, W. Examining the impact of destructive acts in marketing channel relationships. Journal of Marketing Research, v. 38, p. 45-61, 2001. 
HOUBRICH, M. Implementação de um sistema CRM em uma indústria petroquímica de $2^{a}$ geração. 2002. 88f. Dissertação (Mestrado Profissionalizante em Engenharia), Universidade Federal do Rio Grande do Sul, Porto Alegre, 2002.

\section{KARSAKLIAN, E. Comportamento do}

consumidor. 2. ed. São Paulo: Atlas, 2004.

KOTLER, P. Marketing para o século XXI: como criar, conquistar e dominar mercados. Tradução de Cristina Bazán. São Paulo: Futura, 2000.

KOTLER, P.; KELLER, K. L. Administração de marketing. Tradução de Mônica Rosenberg, Claudia Freire e Brasil Ramos Fernandes. 12. ed. São Paulo: Pearson Prentice Hall, 2006.

LAUDON, K. C.; LAUDON, J. P. Sistemas de informação. Rio de Janeiro: Livros Técnicos e Científicos, 1999.

LEWIS, J. D. A empresa conectada: como as empresas líderes vencem através da aliança cliente-fornecedor. Tradução de Antonio T. Carneiro. São Paulo: Pioneira, 1997.

MORGAN, R. M.; HUNT, S. D. The commitment-trust theory of relationship marketing. Journal of Marketing, n. 58, p. 2038, jul. 1994.

NETO, M. R. Construção e teste de um modelo teórico de marketing de relacionamento para o setor de educação. 2003. 171f. Dissertação (Mestrado em Administração)-Faculdade de Administração, Universidade Federal de Pernambuco, Recife, 2003.

OLIVEIRA, L. R. Estudo conceitual da aplicabilidade de CRM em instituições de ensino superior. Revista Análise, Porto Alegre, v.13, 2002.

PEPPERS, D.; ROGERS, M. CRM series: marketing. 2. ed. Rev. Amp. São Paulo: Makron, 2001.

PEPPERS, D.; ROGERS, M.; DORF, B. Marketing One to One: ferramentas para implementação de programas de marketing direto One to One. Tradução de Ernesto Yoshida e Maria Cristina Vondriak. São Paulo: Makron Books, 2001.
REICHHELD, F. Learning from customer defections. Harvard Business Review, p. 56-69, 1996.

REINARES, P. Os 100 erros do CRM: mitos, mentiras e verdades. Tradução de Vértice Translate. São Paulo: Thomson Learning, 2007.

ROESCH, S. M. A. Projetos de estágio e de pesquisa em administração: guia para estágios, trabalhos de conclusão, dissertações e estudos de caso. 3. ed. São Paulo: Atlas, 2006.

SANTOS, C. P.; FERNANDES, D. V. D. H. A recuperação de serviços como ferramenta de relacionamento e seu impacto na confiança e lealdade dos clientes. RAE, São Paulo, v. 48, n. 1, jan./mar. 2008.

SOWINSKI, L. Customer relationship management software. World Trade, jun. 2000.

SRINIVASAN, R.; MOORMAN, C. Strategic firm commitments and rewards for customer relationship management in online retailing. Journal of Marketing, v. 69, p. 193-200, Oct. 2005.

STONE, M.; WOODCOCK, N. Marketing de relacionamento. Tradução de Luiz Liske. 3. ed. São Paulo: Littera Mundi, 1998.

STRAUSS, J.; EL-ANSARY, A.; FROST, R.

E-Marketing. 3. Ed. New York: Prentice Hall, 2003.

TEIXEIRA, E. Gestão de Vendas. Rio de Janeiro: FGV, 2006.

VAVRA. T. G. Marketing de relacionamento: como manter a fidelidade de clientes através do marketing de relacionamento. Tradução de Ailton Bomfim Brandão. São Paulo: Atlas, 1993.

YIN, R. K. Estudo de caso: planejamento e métodos. Tradução de Daniel Grassi. 3. ed. Porto Alegre: Bookman, 2005.

\section{ZENONE, L. C. CRM - Customer Relationship}

Management: gestão do relacionamento com o cliente e a competitividade empresarial. São Paulo: Novatec, 2007. 